\title{
Repercussões do Câncer Infantil sobre a Relação Conjugal ${ }^{1}$
}

\author{
Bárbara Cristina Steffen Rech ${ }^{2}$ \\ Isabela Machado da Silva \\ Rita de Cássia Sobreira Lopes \\ Universidade Federal do Rio Grande do Sul
}

\begin{abstract}
RESUMO - Investigaram-se as repercussões do câncer de um filho sobre a relação conjugal dos pais. Realizou-se um estudo de caso coletivo com quatro casais. Os dados foram obtidos a partir de entrevistas semiestruturadas, realizadas individualmente com cada cônjuge, no ambiente hospitalar. Após, foram submetidos à análise de conteúdo qualitativa, que teve como categorias: coesão, comunicação e intimidade/sexualidade. Relatou-se uma maior coesão, relacionada à sensação de poder contar com o cônjuge. Quanto à comunicação, constatou-se o predomínio de temas relacionados à enfermidade da criança, mas um silenciamento, entre os homens, quanto aos temores vivenciados. A intimidade/sexualidade mostrou-se influenciada pela ansiedade enfrentada. Constatou-se como o câncer infantil pode exacerbar características já presentes na relação, assim como apresentar novos desafios aos casais.
\end{abstract}

Palavras-chave: câncer infantil, relação conjugal, coesão, comunicação, sexualidade

\section{Repercussions of Pediatric Cancer on Marital Relations}

\begin{abstract}
The repercussions of child's cancer on parent's marital relation were investigated. A collective case study with four couples was carried out. Data were obtained from individual semi-structured interviews, conducted in the hospital, and submitted to a qualitative content analysis, whose categories were: cohesion, communication, and intimacy/sexuality. An increase in the cohesion between the parents was observed. In relation to communication, a predominance of topics related to the child's disease was observed. Among the men, silence about their own fears was observed. The intimacy/sexuality was affected by the anxiety about the child's survival. It was shown how child's cancer can intensify characteristics already present in the marital relation, and can also raise new challenges for the couple.
\end{abstract}

Keywords: childhood cancer, marital relations, cohesion, communication, sexuality

O câncer pediátrico é definido como toda neoplasia maligna que acomete indivíduos menores de 15 anos (Elman \& Silva, 2007). Diferente do câncer em adultos, o câncer na criança geralmente afeta as células do sistema sanguíneo e os tecidos de sustentação. A leucemia é o tipo de câncer mais comum nessa população (Rodrigues \& De Camargo, 2003), seguida pelos linfomas (Reis, Santos, \& Thuler, 2007), que se dividem em linfoma Hodking e linfoma não-Hodking, o tipo mais comum na infância (Jadgar \& Shulkin, 2007).

Mesmo diante dos avanços tecnológicos, o câncer continua sendo considerado uma doença ameaçadora à vida (D’Angio, 2007). No caso do câncer infantil, embora exista um bom prognóstico, o tratamento ainda hoje tende a ser longo, doloroso e perigoso (Patterson, Holm, \& Gurney, 2004).

O diagnóstico de uma doença grave é um estressor que mobiliza todo o sistema familiar, especialmente quando o enfermo é uma criança (Lopes \& Valle, 2001). Estudos (Brown, 1995; Rando, 1985; Rolland, 1998; Walsh \& McGoldrick, 1998) têm mostrado que, por inverter a ordem natural da vida, o anúncio de que um filho tem câncer ainda

1 Trabalho derivado da dissertação de mestrado da primeira autora, orientada pela terceira. Apoio: CNPq e Capes.

2 Endereço para correspondência: UFRGS, PPG PSICOLOGIA, Profa. Rita de Cássia Sobreira Lopes, Rua Ramiro Barcellos, 2600, Sala 108, Bairro Santa Cecília, Porto Alegre, RS. CEP 90035-03. E-mail:psi.barbara@gmail.com tende a ser uma experiência tão dolorosa e perturbadora quanto a própria morte, o que pode ameaçar a relação de qualquer casal (Bromberg, 1994; Walsh, 2002). Durante o tratamento da criança, os cuidados a ela oferecidos diminuem bastante o tempo, a energia e o afeto direcionados aos cônjuges (Steffen \& Castoldi, 2006). Tal configuração, além de afetar o sistema conjugal, pode interferir na aliança parental (Rosman, 1991).

Para compreender a forma como o diagnóstico de câncer de um filho pode impactar a relação conjugal de seus pais, é possível recorrer a pressupostos da Teoria Familiar Sistêmica. De acordo com essa abordagem, a família é composta por uma série de subsistemas que se influenciam mutuamente. Exemplos desses subsistemas são o conjugal e o parental. O primeiro diz respeito à relação do casal como companheiros que buscam a satisfação de suas necessidades mútuas; o segundo, à forma como o casal se relaciona entre si e com seus filhos enquanto pais, que compartilham a tarefa de educar e cuidar da criança (Minuchin, 1990). Dada à influência recíproca existente entre os subsistemas, espera-se que eventos ocorridos no subsistema parental venham a repercutir em diferentes dimensões do subsistema conjugal e vice-versa (Minuchin, 1990). Pressupõe-se, assim, que o câncer de um filho, tido como um grande estressor no subsistema parental, venha a impactar também a relação conjugal de seus pais. 
Os resultados obtidos por pesquisas que investigaram essa questão têm se mostrado divergentes (Long \& Marsland, 2011). De acordo com Kaplan, Smith, Grobstein e Fischman (1973), 70\% dos pais de crianças com câncer apresentam sérios problemas conjugais, incluindo altos índices de divórcio. A ideia de que o câncer infantil poderia funcionar como um facilitador para a separação dos pais também se mostraria presente, inclusive, entre os profissionais que trabalham junto a essa população (Rivero-Vergne, Berrios, \& Romero, 2008). Segundo Clulow (1991), a incidência de casamentos rompidos após a morte da criança, ou após a remissão do câncer, pode estar relacionada ao grande investimento despendido durante o tratamento, sendo que, quando termina a batalha pela sobrevivência do filho, o sentido do casamento também pode cessar.

No entanto, outros estudos têm questionado esses resultados. Apesar de reconhecer que a conjugalidade sofre influências, constata-se que diferentes casais tendem a vivenciar de forma diversa o impacto dessa experiência (Long \& Marslang, 2011; Schwab, 1998). Entre os elementos que podem ser relevantes para a compreensão da forma como cada casal reagirá, encontram-se a qualidade da relação conjugal anterior ao diagnóstico (Long \& Marsland, 2011; Sloper, 1996), o apoio emocional existente entre os cônjuges e o próprio apoio social disponível (Dahlquist et al., 1993; Dahlquist, Czyzewski, \& Jones, 1996; Grootenhuis \& Last, 1997; Lavee, 2005).

O estágio da doença atravessado pelo casal e os resultados do tratamento também têm se mostrado relevantes. Os maiores efeitos sobre a relação conjugal têm sido registrados na fase do diagnóstico (Dahlquist et al., 1993), quando o casal passa por um forte abalo, que pode levar tanto a uma maior tensão como a um aumento da coesão entre os cônjuges (Lavee \& Mey-Dan, 2003). Em seu estudo com casais que vivenciavam os primeiros meses de tratamento do filho, Sloper (1996) identificou que 70\% dos pais perceberam a família mais próxima após o diagnóstico. Quanto ao relacionamento conjugal, a maioria (56\%) não percebeu mudança, mas $30 \%$ dos casais apontaram para o aumento de conflitos conjugais decorrentes da doença. Eiser (2004) também identificou um provável surgimento ou aumento de situações de estresse conjugal como efeitos imediatos do diagnóstico de câncer de um filho. No entanto, ao considerar aqueles casais em que o tratamento quimioterápico do filho foi bem sucedido, essa autora constatou que a maior parte dos estudos sugere um aumento na coesão conjugal e familiar.

Além disso, diferentes dimensões da relação conjugal parecem ser impactadas de forma particular pela experiência de câncer de um filho. Lavee e Mey-Dan (2003) constataram que, segundo os participantes de seu estudo, a dimensão conjugal mais prejudicada seria a sexualidade. Por outro lado, esses autores encontraram casais cuja percepção foi de melhora na comunicação, no apoio entre cônjuges e na divisão de responsabilidades, aspectos que proporcionaram uma sensação de fortalecimento da relação conjugal. Outras investigações, porém, revelaram significativo aumento da insatisfação conjugal no período de seis (Kamps \& Klip, 1998) e 12 meses (Hoekstra-Weebers, Jaspers, Kamps, \& Klip, 1998) após o diagnóstico da criança, embora esse resultado não tenha se mostrado verdadeiro para todos os casais (Hoekstra-Weebers et al., 1998).

Embora o impacto do câncer sobre o grupo familiar atualmente seja um tema bastante investigado na área da oncologia pediátrica, a maioria dos estudos aborda a questão sob a perspectiva parental e não conjugal. As mudanças nos padrões de relacionamento conjugal têm estado no centro das investigações de poucos estudos. Em uma recente revisão da literatura, Silva, Jacob e Nascimento (2011) identificaram apenas 14 estudos, publicados entre 1997 e 2009, enfocando o impacto do câncer infantil sobre a relação conjugal dos pais, sendo que, dentre estes, apenas dois foram conduzidos no Brasil.

Destaca-se, ainda, a necessidade de investigar as repercussões desse fenômeno sobre as diferentes dimensões da relação conjugal. Ao revisar diversos estudos, Olson (1991) concluiu que seria possível sintetizar as diferentes variáveis comumente investigadas em pesquisas sobre as relações familiares e conjugais em um modelo composto por três dimensões: a coesão, que se refere ao grau de ligação entre os membros da família; a adaptabilidade, que remete à capacidade de adaptação frente a mudanças e a comunicação, que interfere de forma positiva ou negativa nas outras dimensões. No que se refere especificamente à conjugalidade, outra importante dimensão a ser considerada refere-se à intimidade/ sexualidade (Bradt, 1995).

A partir do modelo proposto por Olson (1991) e dos estudos revisados, optou-se por enfocar, neste trabalho: a) a coesão do casal, b) sua comunicação e c) sua intimidade/ sexualidade. Privilegiando-se uma abordagem desenvolvimental da família e do casal (eg., Carter \& McGoldrick, 1995), os dados foram contextualizados a partir de informações relativas à história do casal e de sua família de origem. Esse modelo já foi utilizado em outros estudos voltados a casais diante de eventos estressores (Silva \& Lopes, 2011), mostrando-se adequado.

Assim, este estudo teve como objetivo investigar as repercussões do câncer de um filho sobre o relacionamento conjugal dos pais, especificamente no que se refere à coesão, à comunicação e à intimidade/sexualidade. Considerando-se os fundamentos da Teoria Sistêmica, assim como os estudos revisados, acredita-se que o câncer de um filho tenda a repercutir de forma diversa nas diferentes dimensões da relação conjugal.

\section{Método}

\section{Participantes}

Participaram deste estudo quatro casais, cujos filhos estavam realizando tratamento oncológico em um hospital pediátrico de Porto Alegre/RS que atende pacientes pelo Sistema Único de Saúde (SUS). Foram incluídos pais de pacientes com idades entre 3 e 6 anos e com diagnóstico recente de leucemia ou de linfomas não Hodgkin, por serem estes os tipos de câncer com maior incidência entre crianças, além de possuírem prognóstico semelhante. Os casais eram domiciliados no mesmo endereço, junto com seus filhos. 
Os casos foram selecionados de acordo com o critério de heterogeneidade, proposto por Patton (2002), que se caracteriza pela composição da amostra a partir da seleção de casos que sejam diferentes entre si em características consideradas relevantes. De acordo com esse autor, essa estratégia de seleção favorece a identificação de temas centrais ao contexto estudado, os quais permanecem presentes apesar das diferenças existentes. Neste trabalho, os participantes variaram quanto à configuração conjugal e familiar, o tempo de união, a idade, o nível socioeconômico e o tipo de neoplasia da criança. Salienta-se que não foram incluídos casos em que a doença estivesse em fase avançada ou evidenciando sinais de terminalidade, visto que o objetivo era trabalhar no momento mais próximo possível à fase diagnóstica. Por ocasião das coletas, as crianças estavam em tratamento, porém não hospitalizadas, por ser intervalo dos ciclos de quimioterapia. As entrevistas foram realizadas nos dias em que os pais levavam seus filhos à consulta ambulatorial.

Casal 1. À época da realização do estudo, Marcos e Rosa ${ }^{3}$ estavam juntos há mais de 15 anos. Ambos se encontravam na faixa dos 30 anos e possuíam o ensino fundamental incompleto. Seu nível socioeconômico era considerado baixo ${ }^{4}$, sendo pais de três filhos. Seu filho caçula, Wagner, estava com 6 anos e fora diagnosticado com Linfoma de Burkit há sete meses.

Casal 2. Márcio e Elaine estavam juntos há aproximadamente cinco anos. Ele se encontrava na faixa dos 30 anos e ela, na dos 20, ambos possuíam ensino fundamental incompleto. Seu nível socioeconômico era considerado baixo. Seu único filho, Willian, tinha 3 anos e fora diagnosticado com Leucemia há 11 meses.

Casal 3. João Ricardo e Cleusa estavam juntos há mais de cinco anos. Ambos se encontravam na faixa dos 30 anos, ele possuía o ensino médio incompleto e ela, o ensino médio completo. Seu nível socioeconômico era médio. Um dos cônjuges possuía filhos de outro relacionamento. A única filha do casal, Kelly, tinha 3 anos e fora diagnosticada com Leucemia há quatro meses.

Casal 4. Marcony e Jane estavam juntos há aproximadamente cinco anos. Ambos se encontravam na faixa dos 20 anos, ele possuía o ensino médio incompleto e ela, o ensino fundamental incompleto. Seu nível socioeconômico era considerado médio baixo. Seu único filho, Lucas, tinha 3 anos e fora diagnosticado com Leucemia há dois meses.

\section{Delineamento e Procedimentos}

Realizou-se um estudo de caso coletivo (Stake, 1994), que teve como objetivo investigar tanto as semelhanças entre os casos, como suas particularidades. Os casais foram contatados na unidade de tratamento oncológico do hospital. O contato inicial foi feito por intermédio da psicóloga dessa instituição, que indicou os possíveis participantes.

3 Para preservar o sigilo dos participantes, os nomes utilizados nesse artigo são fictícios.

4 O nível socioeconômico foi avaliado a partir da adaptação das categorias de Hollingshead proposta por Tudge e Frizzo (2002), a qual se baseia na escolaridade e nas profissões dos participantes. Nessa escala, os casais se enquadraram respectivamente nas categorias $1,1,3$ e 2 .
Identificaram-se nove casais como potenciais participantes. Desses, dois foram excluídos da amostra por não atenderem aos critérios de inclusão - em um, o filho se encontrava em estado terminal e, no outro, o casal estava se separando - e dois não aceitaram participar do estudo, justificando sua recusa em função da pouca disponibilidade de tempo e da dificuldade em falar sobre um assunto tão delicado.

Uma vez confirmado o interesse de participação e os critérios de inclusão no estudo, agendavam-se os encontros para início dos procedimentos de coleta de dados. Os encontros eram realizados individualmente com cada cônjuge e, à exceção de uma entrevista, ocorreram no hospital. As entrevistas tiveram, em média, 60 minutos de duração, tendo sido realizadas na sala de reuniões do Ambulatório de Oncologia do Hospital. A opção por entrevistar os cônjuges individualmente justificou-se pelo fato de cada pessoa enfrentar situações de sofrimento a seu modo. Assim, almejou-se facilitar a livre expressão, sem que os cônjuges tivessem de se preocupar com o possível impacto emocional de sua fala sobre o outro. O Termo de Consentimento Livre e Esclarecido (TCLE) foi lido e assinado no início do primeiro encontro com cada um dos participantes. Após, realizavam-se as entrevistas, o que se estendia por dois encontros com cada participante. As aplicações dos instrumentos foram gravadas em áudio e posteriormente transcritas para fins de análise.

O presente estudo respeita as diretrizes definidas pela Comissão Nacional de Pesquisa (1996). O projeto foi aprovado por comitê de ética autorizado pela Comissão Nacional de Ética em Pesquisa (CONEP), em 10 de abril de 2008, sob o protocolo 1785/08. No TCLE assinado pelos participantes, assegurou-se a voluntariedade de sua participação, assim como seu direito a se retirar do estudo sem qualquer prejuízo a seu atendimento no hospital.

\section{Instrumentos}

Os participantes responderam à Entrevista de Dados Demográficos do Casal (NUDIF, 1998), que tem como objetivo coletar informações sociodemográficas, tais como idade, escolaridade, situação profissional, moradia, tempo de união conjugal e data do diagnóstico do filho. Cada um dos cônjuges também respondeu individualmente a Entrevista sobre o Impacto da Doença Grave de um Filho sobre a Relação Conjugal (Rech \& Lopes, 2007, adaptada de Lopes \& Menezes, 2003). Trata-se de uma entrevista semiestruturada, que tem como objetivo investigar o impacto do diagnóstico de câncer infantil e do acompanhamento do tratamento sobre a relação conjugal, através de questões organizadas em quatro eixos: a) história da relação, b) nascimento do filho, c) diagnóstico de doença grave do filho e d) consequências dessa experiência.

\section{Análise dos Dados}

Os dados obtidos por meio das entrevistas foram submetidos à análise de conteúdo qualitativa (Laville \& Dione, 1999). A definição das categorias analíticas ocorreu a partir do modelo misto proposto por Laville e Dione. Assim, as 
categorias foram inicialmente definidas com base na literatura e na estrutura dos instrumentos, sendo posteriormente aprimoradas de acordo com a análise dos dados.

A análise dos dados teve como objetivo descrever diferentes dimensões da relação conjugal, as quais foram contextualizadas a partir de informações acerca da história do casal. A seguir, são apresentadas as descrições das três dimensões avaliadas:

a) Coesão (Olson, 2000; Ríos-González, 2005): Descreve os conteúdos que revelam os sentimentos que unem o casal, sua percepção de proximidade em relação ao outro, a percepção de apoio oferecido e recebido entre ambos, as atividades conjuntas dos cônjuges e as fronteiras que separam os subsistemas conjugal e parental, bem como a individualidade e a conjugalidade.

b) Comunicação (Nichols, 2005; Olson, 1991): Descreve o padrão de comunicação existente entre os cônjuges com especial atenção aos processos verbais e não-verbais presentes na relação e que são expressos através de conversas, manifestações comportamentais, expressão de emoções e pela forma como resolvem seus problemas e conflitos.

c) Intimidade/Sexualidade (Bradt, 1995): Descreve os conteúdos referentes à vida sexual do casal, às suas demonstrações de carinho, bem como expressões de vivência da intimidade conjugal.

\section{Resultados e Discussão}

Os resultados serão apresentados e discutidos levando em consideração as três dimensões de interesse deste trabalho. Aborda-se como essas dimensões se mostraram ao longo da história do casal, assim como as modificações vivenciadas após o diagnóstico de câncer do filho.

\section{Coesão}

Ao longo de um relacionamento, diversos aspectos da conjugalidade passam por modificações, tendo em vista a adaptação tanto a estressores inesperados quanto a situações normativas das etapas do ciclo vital e familiar (Carter \& McGoldrick, 1995; Olson, 2000). No presente estudo, a crise instalada pelo diagnóstico de câncer infantil aproximou os casais participantes, promovendo um incremento da coesão.

Eu penso que o sofrimento une mais as pessoas do que a própria alegria. Quando tu está sofrendo tu quer compartilhar com aquela pessoa que está do teu lado (...) Eu acho que foi isso que uniu mais, até por esse fato de a Kelly precisar dos dois, de a gente precisar um do outro pra ajudar a Kelly (Cleusa, Casal 3).

Ao relatar aumento da união em decorrência da enfermidade do filho, tais casais corroboram os achados de Rolland (1995). Segundo esse autor, o diagnóstico de câncer infantil tenderia a aproximar o núcleo familiar, exercendo, assim, uma ação centrípeta.
O incremento da coesão conjugal também pode ser explicado pela identidade conjugal construída anteriormente ao diagnóstico. Assim, o Casal 1 destacou a existência de um "jeito nosso" - que poderia ser traduzido como identidade conjugal, que permanece inalterado apesar da adversidade por eles enfrentada. Nesse "jeito" estão incluídos o afeto, as funções desempenhadas por ambos, o "costume" de estarem juntos e o ciúme do marido para com a esposa. Este casal demonstrou ser sua filosofia de vida a ideia de que independente do que aconteça, é preciso "seguir" e "ir levando a vida como era antes". Por sua vez, para os casais 3 e 4, a experiência da doença do filho motivou reestruturações, as quais resultaram em melhoras para o sistema familiar como um todo.

O Casal 4 modificou sua maneira de se relacionar ao constatar que, para apoiar o filho, precisariam estar "bastante unidos". Neste casal, a necessidade de enfrentamento da doença promoveu a ampliação do espaço familiar e conjugal, de forma que o marido passou a oferecer mais atenção à esposa e ao filho.

Eu acho que a gente se uniu mais ainda, acho que dali a gente tirou mais força pra gente se unir. O relacionamento ficou mais forte, agora a gente se uniu bastante para dar apoio pro meu filho (Marcony, Casal 4).

A coesão tende a auxiliar no enfrentamento de situações estressantes, pois os casais demonstram superar tamanha adversidade justamente por poderem contar com seu cônjuge. União e sentimento de "poder contar com o outro" demonstram ser aspectos favorecedores do funcionamento familiar diante de estressores (Walsh, 2006), sendo a coesão familiar relevante, inclusive, para a proteção da saúde psicológica de pais que cuidam de um filho com câncer (Klassen, et al., 2007).

Postula-se que, ao enfrentar situações conflituosas ou adversas, a qualidade do vínculo inicial existente entre os cônjuges exerce papel central para a manutenção da relação (Hintz, 1999). Na história dos quatro casais participantes deste estudo, constatou-se a existência de uma característica marcante desde o início dos relacionamentos: a centralidade dos filhos e, por conseguinte, do subsistema parental. São casais que passaram pelo ritual de casamento motivados pela chegada do seu filho, o que, segundo eles, conferiu estabilidade à relação, conforme pode ser observado na fala de Cleusa (Casal 3), ao se referir ao nascimento da filha:

A relação ficou mais estável, eu tive mais segurança. Depois
que eu tive a Kelly, não sei se foi a casualidade de ter a Kelly,
ou a segurança que eu acho que, entre aspas, a Kelly me deu,
que eu comecei a... ou eu amadureci, eu não sei o que foi.

Outra semelhança é que os casais já tinham enfrentado situações difíceis ao longo da vida, sendo que as tinham superado de modo avaliado como positivo. Exemplo disso é o Casal 1 que, devido à forma como se apoiaram em experiências difíceis ao longo de sua vida (como a perda de um bebê durante a gravidez), guardava a certeza de que sempre poderiam continuar a contar um com o outro nos momentos de fragilidade. Esse é um fator de grande importância e for- 
talecedor da união, pois, quando o casal ou família conta com histórico de superação de estressores no seu passado, tende a ficar mais confiante quanto ao enfrentamento de situações futuras (Patterson, 2002).

\section{Comunicação}

O diagnóstico de uma doença grave, como é o câncer, influencia o padrão comunicacional dos cônjuges, podendo tanto criar uma comunicação mais plena e profunda, como apresentar o efeito oposto, com a vivência silenciosa, e, por vezes, solitária da experiência (LeShan, 1992). No caso dos casais participantes deste estudo, foi possível constatar, em todos os casos, a propensão à permanência do padrão de interação conjugal tal como era antes do diagnóstico de câncer do filho. Na história desses casais, percebeu-se a tendência de as esposas expressarem mais suas emoções verbalmente, enquanto os maridos, com a intenção de proteger as esposas, guardavam mais suas preocupações para si. Diante do diagnóstico de câncer de seus filhos, os maridos mantiveram sua postura de não partilharem com suas esposas os temores com relação ao futuro da criança, desejando protegê-las de um possível aumento de sua dor. Como demonstra a fala de João Ricardo (Casal 3):

A minha esposa explode, dá muitos sintomas nela-nervosismo, chora, entra em desespero. Então, eu procuro ficar para mim. [Nos momentos piores] eu guardava os sentimentos pra mim pra não passar mais um problema. A Cleusa é mais sentimental, mais emotiva. Então, procuro preservar um pouco.

As esposas também manifestaram tendência à continuidade do padrão comunicacional desenvolvido pelo casal. Elas permaneceram manifestando abertamente seus sentimentos, preocupações e pensamentos sobre o futuro dos filhos: "Quando estava preocupada com isso ou com aquilo, eu sempre conversei com ele. Ah, eu falo... tem momentos que eu desabo, que eu não quero saber" (Cleusa, Casal 3).

Elaine (Casal 2) reconheceu que, caso seu marido fosse tão ansioso quanto ela, ambos "iriam à loucura". Para essa esposa, a tranquilidade do marido serviu como um "amortecedor" (Dahlquist et al., 1993) para sua ansiedade e ofereceu ao casal a possibilidade de manterem-se relativamente bem ao longo do período de tratamento do câncer do filho.

De acordo com Silva et al. (2011), tem-se verificado na literatura uma maior dificuldade por parte dos pais em compartilhar seus sentimentos com a esposa frente à situação de câncer de um filho. Nossos resultados, porém, ao considerarem os relatos desses casais acerca de sua história, demonstram que essa é uma característica que já se mostrava presente antes mesmo do adoecimento da criança, não devendo, assim, ser considerada exclusivamente como uma consequência da situação enfrentada.

Os participantes apresentam-se, portanto, como casais complementares (Minuchin \& Fishman, 1990). Um casal complementar seria aquele em que cada cônjuge assume características opostas, formando uma dupla que se completa (Elkaim, 1998; Minuchin \& Fishman, 1990). É importante considerar que a complementaridade guarda aspectos tanto positivos como negativos, uma vez que, em alguns casos, pode enrijecer a relação, limitando o padrão de interação dos cônjuges. Esta seria uma complementaridade disfuncional, na medida em que um restringiria o outro, dificultando sua diferenciação e autonomia (Stierlin, Weber, Schmidt, \& Simon, 1986).

Dentre as mudanças constatadas na dimensão da comunicação após o diagnóstico está a mudança nos temas abordados pelo casal. Ainda que sempre tenham priorizado seus filhos, com a doença, os assuntos passaram a ser exclusivamente voltados à criança enferma e seu tratamento: "Era 100\% voltado para a Kelly; não se pensava em outra coisa a não ser nela" (João Ricardo, Casal 3); "Ele me ligava todos os dias. Ele perguntava se o William estava bem, se ele estava reagindo bem. Aí ele dizia que não era pra eu ficar nervosa, que o que era para ser nosso, Deus não tirava" (Elaine, Casal 2).

Há que se considerar que, pela distância física, boa parte da comunicação era feita via telefone e, quando tinham a oportunidade de se encontrar, os casais conversavam pouco, devido às circunstâncias impostas pelo ambiente hospitalar: várias pessoas no quarto (os participantes eram usuários do SUS), horários restritos de visitas. Assim, incorporavam um ritmo próprio das urgências hospitalares.

A gente conversava pouco. Entre três pacientes num quarto, não tem como dialogar. O que é feito é praticamente trabalho de vigilante: tu chega, passa a situação do dia e tchau. [Sobre] nós dois não se pensava, era um beijo e te amo e tchau (João Ricardo, Casal 3).

Nessa circunstância, pode-se estabelecer um paralelo entre o nascimento de um filho e o recebimento de um diagnóstico de doença grave: assim como na chegada de um filho existe diminuição de tempo destinado ao exercício da conjugalidade (Shapiro, Gottman, \& Carrère, 2000), o mesmo ocorre frente ao diagnóstico (Steffen \& Castoldi, 2006). Isso porque a "troca de plantões" feita entre os pais restringe a comunicação dos cônjuges.

Outra mudança constatada na dimensão da comunicação foi o aumento de desentendimentos, o que, conforme os participantes, estaria relacionado ao nervosismo decorrente dos temores referentes à doença do filho: "O relacionamento fica assim mais... Eu, principalmente, sou muito nervosa. E o Marcos também, mas ele não demonstra tanto. E eu já me estouro, às vezes, em casa. Daí ele fica brabo comigo. É que eu me estresso com ele" (Rosa, Casal 1)

Da mesma forma João Ricardo (Casal 3) admitiu que "alguns momentos explosivos" ocorreram, no entanto não tão graves a ponto de "prejudicar alguma coisa". Ainda que os casais participantes demonstrassem consciência de que suas manifestações não condiziam com o que, de fato, estava incomodando (a ameaça de perda do filho), não conseguiam evitar o conflito. Segundo Satir (1993), esse seria um comportamento incongruente, pois não existe coerência entre o motivo e a ação resultante. Ou seja, nesses casos, a irritação não seria com o cônjuge, mas este era o escolhido para a liberação das tensões. 
Importante considerar que nem sempre é fácil ouvir o que o companheiro tem a dizer, visto que, provavelmente, ele queira falar de seus medos com relação ao tratamento do filho. Sobremaneira nos momentos em que os resultados não são positivos, a questão da morte interpõe-se e então o diálogo, não raras vezes, fica bastante prejudicado. Tal fato foi constatado em pesquisas anteriores, nas quais tanto crises repentinas como situações de estresse prolongado predispuseram casais à mudança nos padrões de comunicação, muitas vezes reduzindo as interações ao máximo, exatamente nos momentos em que ela seria mais essencial (Steffen \& Castoldi, 2006; Walsh, 2006). No presente estudo, verificou-se essa tendência principalmente por parte dos maridos, no entanto, a mesma refletiu um padrão já presente no casal anteriormente.

$\mathrm{Na}$ medida em que os casais foram percebendo os sinais de melhora dos seus filhos, também se sentiram mais encorajados a trocar ideias a respeito do tratamento. Isso porque, à proporção que a possibilidade de perda vai sendo afastada, a esperança aumenta e, com ela, o casal tende a buscar um estilo de vida o mais próximo possível do que era antes da doença.

Um aspecto a ser destacado nos casais participantes foi que, diferente do esperado, os cônjuges não atribuíram culpa um ao outro pela origem da doença da criança. Todos aceitaram as explicações oferecidas pela equipe, que lhes informou ser o câncer uma doença de múltiplas causas, não apenas genéticas, mas uma doença multifatorial. Por isso, cada um buscou um sentido para lidar com a experiência, sem agredir o cônjuge com as compreensões feitas por si. Exemplo disso é o Casal 3, em que ambos passaram a acreditar que a doença surgiu em suas vidas a fim de aproximá-los e torná-los "mais família". É possível pensar que atribuições como essa tenham ajudado o casal a lidar com os desafios enfrentados.

\section{Intimidade/Sexualidade}

A fase de diagnóstico e tratamento do câncer dos filhos exerceu influência de diferentes ordens na intimidade/sexualidade dos casais, sendo a ansiedade referente ao futuro do filho o principal elemento desafiador a essa dimensão. Tal dimensão demonstrou ser a mais impactada nos casais participantes, corroborando estudos anteriores (Lavee \& Mey-Dan, 2003).

Eu fico nervosa, dai o Marcos se invoca. Se a gente está nervosa com uma coisa, ou, se tu está encucada com alguma coisa, já não adianta nem tentar. Mas o homem já não é assim, sei lá, pode estar preocupado ou não, para eles é a mesma coisa, parece (Rosa, Casal 1)

Além disso, a atenção voltada às necessidades do filho enfermo fez com que a relação conjugal dos casais fosse colocada em segundo plano: "A gente procurava se privar de muitas coisas. E a nossa preocupação era com a nossa filha" (João Ricardo, Casal 3).

Esse casal chegou a afirmar que o comportamento sexual foi suspenso durante o período inicial, de diagnóstico e familiarização com o tratamento oncológico. João Ricardo esclareceu que a doença da filha fez com que todo o restante fosse "esquecido" por um tempo. Sua esposa mencionou que, caso tivessem optado por desfrutar de um momento íntimo, de prazer, enquanto a filha precisava deles, provavelmente se sentiriam culpados. Sendo assim, o primeiro mês de internação "passou batido" na parte sexual, sendo que os demais casais viveram experiência semelhante a essa.

Cabe destacar, porém, que, desde o início, a história dos casais participantes foi marcada pela centralidade dos filhos em suas vidas. Em todos os casais participantes, os filhos partilhavam o quarto conjugal desde seu nascimento. Trata-se, assim, de casais que adequaram sua vida sexual à presença do filho. Assim como antes do diagnóstico, esses casais precisavam aproveitar os momentos em que os filhos não estavam por perto para vivenciar essa dimensão; após o diagnóstico, a vivência da sexualidade seguiu organizada ao redor da criança e de suas necessidades. Nos intervalos entre as internações, por exemplo, identificou-se que chegar em casa com a criança enferma despertou inseguranças quanto à melhor maneira de cuidá-la, de forma que todas elas permaneceram dormindo no quarto dos pais.

No Casal 2, também percebeu-se que, a partir do diagnóstico, o garoto passou a receber mais atenção, tornando-se, por isso, "mais baldoso", segundo as palavras de Elaine. $\mathrm{O}$ fato de o filho desejar ser o centro das atenções, mesmo quando estava bem, passou a interferir na sexualidade dos pais. Além de ele estar "grande" e "esperto", Elaine apontou para o fato de o menino ser "bem ciumento". O garoto passou a exercer maior controle sobre os comportamentos de carinho dos pais. Sendo assim, ao escutar o som de um beijo, ver o pai e a mãe se abraçando, ou caminhando de mãos dadas, o menino intervinha, desviando o foco para si. Pode-se pensar que este ficou triangulado com os pais. Isso sugere que, desde o nascimento, William cumpre uma função periférica de regulação da tensão existente na relação do casal. Em função da doença, o estado de insegurança instaurado passou a ocupar um dos vértices do triângulo emocional, sobrepondo-se ao lugar ocupado anteriormente pelo menino. Em razão disso, o casal manteve o menino no quarto, motivado pela mesma justificativa dos outros casais: melhor cuidar do filho. De forma semelhante, o Casal 4, cujo filho nunca saiu da cama dos pais, tanto por motivos socioeconômicos - havia somente um quarto na casa - quanto por questões emocionais, também ocupa um dos vértices do triângulo conjugal. $\mathrm{O}$ fato de estar no quarto dos pais não prediz a "triangulação", mas, sim, a relação que pais e filhos estabelecem entre si. Conforme assinalaram Silva et al. (2011), diferentes estudos sugeriram que os pais tendem a colocar de lado suas dificuldades conjugais prévias em prol do cuidado do filho. Embora tal atitude possa favorecer a união do casal em torno da tarefa de cuidar da criança, a mesma também impede que essas dificuldades sejam diretamente manejadas.

Na medida em que os filhos passaram a apresentar sinais de melhora de sua saúde, os casais também perceberam uma melhora em sua vida sexual: "Mas agora parece que [está] melhor ainda, sabendo que tá tudo bem, e que, se Deus quiser, o tratamento vai acabar logo e ele vai ficar bom" (Elaine, Casal 02).

5 Regionalismo que significa manhoso. 


\section{Considerações Finais}

Este estudo investigou o relacionamento conjugal de casais que enfrentaram o diagnóstico de câncer de um filho, especificamente no que se refere à coesão, à comunicação e à intimidade/sexualidade. Contextualizaram-se as mudanças percebidas a partir dos relatos do casal acerca de sua história.

A relevância dessa contextualização reside no fato de que ela nos permitiu compreender as mudanças e continuidades na vida dos casais, após o diagnóstico. Com base em tais informações, tornou-se possível diferenciar quais transformações dizem respeito à doença e quais características já se mostravam presentes na vida desses casais, assim como identificar aspectos das histórias desses casais que podem ter contribuído para o impacto do diagnóstico.

Os resultados encontrados revelaram incremento da coesão conjugal em decorrência do enfrentamento do câncer infantil. Tal incremento foi valorizado pelos casais, que o consideraram como algo bom, resultante da experiência. Embora os casais já contassem com histórico de apoio mútuo eficiente, estruturado desde o início da relação, o enfrentamento do câncer resultou no fortalecimento da união, segundo sua perspectiva.

No que se refere à comunicação, identificaram-se continuidades e mudanças no padrão de interação conjugal. Os maridos, que antes do diagnóstico de câncer do filho tinham a tendência de ficar calados a fim de proteger as esposas, mantiveram tal atitude. Com o surgimento do estressor, além da "proteção", constatou-se um movimento de silenciamento dos temores relativos à possibilidade de perda do filho. Em relação aos assuntos compartilhados pelo casal, verificou-se uma modificação de foco, que passou a ser direcionado integralmente à criança enferma, a partir do diagnóstico. A consequência disso foi que o filho ficou inteiramente "entre" os membros do casal, aumentando assim sua centralidade em detrimento da conjugalidade.

Também na dimensão da intimidade/sexualidade, constataram-se continuidades e mudanças. $\mathrm{O}$ fato de a relação conjugal como um todo ser colocada em segundo plano ajuda a compreender a influência exercida pelo câncer sobre a vivência da intimidade / sexualidade. Essa é uma dimensão que requer sintonia conjugal e, em meio à dor, torna-se desafiador harmonizar as necessidades emocionais de cada cônjuge.

A centralidade dos filhos já era uma característica existente nesses casais. Mesmo antes do diagnóstico de câncer, as crianças ocupavam o centro das atenções e demonstravam ser filhos muito investidos pelo amor de seus pais. No entanto, devido à doença, esse aspecto foi exacerbado em função da insegurança gerada pelo diagnóstico e pela necessidade de bem cuidá-los. Por conseguinte, destaca-se a permanência das crianças no quarto dos pais, justificada pelo desejo de oferecer a atenção da qual necessitavam. Ter um filho com câncer naturalmente direciona a atenção e energia do casal para ele. Esse fato, somado à experiência de o câncer tornar as crianças mais perceptíveis ao que acontece ao seu redor, pode interferir negativamente no desfrute da intimidade/ sexualidade quando o filho permanece dormindo no quarto dos pais. Por sua vez, a capacidade de reorganização permitiu a retomada do exercício da sexualidade após a fase inicial.

Um dos desafios, no que tange ao futuro dos casais que passam pela experiência de ter um filho com câncer, diz respeito, justamente, à reorganização do padrão de relacionamentos, voltando a equilibrar a atenção dispensada aos subsistemas parental, conjugal e a outros vínculos, como família extensa e amigos, após o término do tratamento. A partir dos nossos dados, é possível propor a existência de três momentos nesse processo: a) cônjuges experienciam individualmente a angústia de ter um filho com a vida ameaçada pelo câncer; b) cada cônjuge se recompõe para se relacionar com o esposo(a) e c) o casal reorganiza sua conjugalidade prévia essencial na elaboração emocional da experiência. Nesse sentido, destacam-se os aspectos saudáveis preservados pelos casais participantes que conseguiram reorganizar-se em curto período. Os cônjuges demonstraram, pois, ser capazes de modificar sua estrutura de poder, papéis e regras de relação, em resposta ao estressor, apresentando o que Olson (2000) denominou de "flexibilidade", a capacidade de se adaptar em prol da saúde emocional de todos os membros da família.

Em relação ao método escolhido para este estudo, algumas considerações podem ser feitas quanto ao seu potencial. Acredita-se que a opção pelo delineamento de estudo de caso coletivo e pela análise qualitativa dos resultados favoreceu a contextualização dos dados (Robson, 1993), assim como a identificação de especificidades e padrões de interação complexos, em função da detalhada coleta de dados que caracteriza essa abordagem (Camic, Rhodes, \& Yardley, 2003). Dessa forma, foi possível compreender a experiência do adoecimento infantil e seu impacto na conjugalidade, bem como o conhecimento de como as pessoas mobilizam forças para lidar com a doença e lutar pela recuperação da saúde.

No que diz respeito à escolha dos casos, seguiu-se o critério de heterogeneidade (Patton, 2002), que permitiu a inclusão de casais com diferentes configurações. Mesmo assim, foram encontradas semelhanças no enfrentamento da adversidade, as quais podem ser consideradas temas centrais a esse contexto por perpassarem casos tão diversos (Patton, 2002). Dessa forma, por contemplar a heterogeneidade, o estudo abrangeu realidades diversas, que se aproximam daquelas encontradas nos hospitais (Silva \& Lopes, 2011). Essas informações mostram-se relevantes não apenas para profissionais da saúde mental, mas para as diversas categorias que trabalham junto a essa população (Silva et al., 2011).

As três dimensões da conjugalidade utilizadas neste estudo (coesão, comunicação e intimidade/sexualidade) mostraram ser eficientes em pesquisas que enfoquem a relação conjugal no enfrentamento de estressores. Além disso, a consideração dessas dimensões contempla a ideia da conjugalidade como um constructo muldimensional (Mossman, Wagner, \& Féres-Carneiro, 2006).

Mesmo que o objetivo do estudo de caso não seja a generalização dos resultados (Stake, 1994), é plausível supor que a descrição e discussão das experiências dos participantes deste estudo possam se mostrar úteis para compreender as vivências de outros casais que se deparam com esse desafio. Os dados obtidos por esta pesquisa, assim como a literatura revisada sugerem a importância da realização de outros estudos que possam aprofundar a compreensão sobre o tema.

Tendo em vista que o tempo de duração do tratamento, a existência ou não de recidiva e a sobreposição de outras demandas podem influenciar a forma como cada cônjuge lida com a situação (Dalquist et al., 1993; Franco, 2008; 
Lavee \& Mey-Dan, 2003), sugere-se que a realização de um estudo longitudinal poderia contribuir para a compreensão do impacto da doença sobre a conjugalidade a longo prazo. Neste estudo, trabalhou-se com casais cujos filhos não haviam passado por nenhuma recidiva e contavam com respostas positivas ao tratamento, e os casais apresentaram uma tendência: quando a criança estava bem, a relação conjugal também estava. Assim, ressalta-se que, mesmo quando a coesão dos casais é incrementada durante o enfrentamento da doença do filho, como o ocorrido, é necessário considerar que, se a possibilidade de perda de um filho retornar ao cenário, a relação poderá ser colocada em risco. A proposta de um estudo longitudinal consistiria, pois, no acompanhamento dos casais desde o diagnóstico até o desfecho da doença. Isso incluiria o acompanhamento de recidivas, óbitos, remissões e o consequente impacto sobre a vida dos casais.

Também teriam muito a contribuir para a compreensão desse tema, estudos que propusessem uma metodologia de triangulação dos dados (Yin, 2005), que consiste na utilização simultânea de diversos procedimentos, a fim de auxiliar na interpretação dos achados. Nesse contexto, poderiam ser utilizados observação e testes projetivos. A observação das interações conjugais facilitaria o acesso às dimensões da comunicação e coesão, posto que tornaria possível comparar os dados observados com as informações obtidas nas entrevistas. Já os testes projetivos poderiam ser eficientes no acesso às ideias daqueles participantes que demonstraram maiores dificuldades de expressão.

\section{Referências}

Bradt, J. O. (1995). Tornando-se pais: Famílias com filhos pequenos. In B. Carter \& M. McGoldrick (Ed.), As mudanças no ciclo de vida familiar: Uma estrutura para a terapia familiar (pp. 206-222). Porto Alegre: Artes Médicas.

Bromberg, M. H. P. F. (1994). A psicoterapia em situações de perdas e luto. São Paulo: Psy II.

Brown, F. H. (1995). Impacto da morte e da doença grave sobre o ciclo de vida familiar. In B. Carter, \& M. McGoldrick (Ed.), As mudanças no ciclo de vida familiar: Uma estrutura para a terapia familiar (pp. 393-414). Porto Alegre: Artes Médicas.

Camic, P. M., Rhodes, J. E., \& Yardley, L. (2003). Naming the stars: Integrating qualitative methods into psychological research. In P. M. Camic, J. E. Rhodes, \& L. Yardley (Eds.), Qualitative research in psychology: Expanding perspectives in methodology and design (pp. 3-15). Washington: American Psychological Association.

Carter, B., \& McGoldrick, M. (1995). As mudanças no ciclo de vida familiar: Uma estrutura para a terapia familiar. In B. Carter, \& M. McGoldrick (Eds.), As mudanças no ciclo de vida familiar: Uma estrutura para a terapia familiar (pp. 07-29). Porto Alegre: Artes Médicas.

Clulow, C. (1991). The chronically ill child and the parents' marriage: Interactive effects. British Journal of Psychotherapy, 7, 331-340.

D'Angio, G. J. (2007). Is childhood cancer a chronic disease? Journal of Pediatric Hematology Oncology, 29, 595-597.
Dahlquist, L., Czyzewski, D., Copeland, K., Jones, C., Taub, E., \& Vaughan, J. (1993). Parents of children newly diagnosed with cancer: Anxiety, coping and marital distress. Journal of Pediatric Psychology, 18, 365-376.

Dahlquist, L. M., Czyzewski, D. I., \& Jones, C. L. (1996). Parents of children with cancer: a longitudinal study of emotional distress, coping style, and marital adjustment two and twenty months after diagnosis. Journal of Pediatric Psychology, 21, 541-554.

Eiser, C. (2004). Children with cancer: The quality of life. Mahwah, NJ: Lawance Erlbaum Associates.

Elkaim, M. (1998). Panorama das terapias familiares. Vol. 1. São Paulo: Summus.

Elman, I., \& Silva, M. E. M. P. (2007). Crianças portadoras de leucemia linfóide aguda: Análise dos limiares de detecção dos gostos básicos. Revista Brasileira de Cancerologia, 53, 297-303.

Franco, M. H. P. (2008). A família em psico-oncologia. In V. A. Carvalho et al. (Eds.), Temas em Psico-oncologia (pp. 358361). São Paulo: Summus.

Grootenhuis, M. A., \& Last, B. F (1997). Parents' emotional reactions related to different prospects for the survival of their children with cancer. Journal of Psychosocial Oncology, 15, 43-62.

Hintz, H. C. (1999). Dinâmica da interação do casal. Pensando Famílias, 1, 31-40.

Hoekstra-Weebers, J., Jaspers, J., Kamps, W., \& Klip, E. (1998). Marital dissatisfaction, psychological distress and the coping of parents of pediatric cancer patients. Journal of Marriage and the Family, 60, 1012-1021.

Kamps, W. A., \& Klip, E. C. (1998). Marital dissatisfaction, psychological distress and the coping of parents of pediatric cancer patients. Journal of Marriage and the Family, 60, 1012-1021.

Kaplan, D. M., Smith, A., Grobstein, R., \& Fischman, S. E. (1973). Family mediation of stress. Social Work, 18, 60-69.

Klassen, A., Raina, P., Reineking, S., Dix, D., Pritchard, S., \& O' Donnell, M. (2007). Developing a literature base to understand the caregiving experience of parents of children with cancer: a systematic review of factors related to parental health and well-being. Support Care Cancer, 15, 807-818.

Jadgar, H., \& Shulkin, B. L. (2007). Pediatric oncology. In S. T. Treves (Ed.), Pediatric nuclear medicine/ PET (pp. 404-418). New York: Springer.

Lavee, Y. (2005). Correlates of change in marital relationships under stress: The case of childhood cancer. Families in Society, 86, 112-120.

Lavee, I., \& Mey-Dan, M. (2003). Patterns of change in marital relationships among parents of children with cancer. Health \& Social Work, 28, 255-263.

Laville, C. \& Dione, J. (1999). A construção do saber: Manual de metodologia da pesquisa em ciências humanas. Porto Alegre: Artes Médicas Sul.

LeShan, L. (1992). O câncer como ponto de mutação: Um manual para pessoas com câncer, seus familiares e profissionais de saúde. São Paulo: Summus.

Long, K. A., \& Marsland, A. L. (2011). Family adjustment to childhood cancer: A systematic review. Clinical Child and Family Psychology Review, 14, 57-88. 
Lopes, R. C. S., \& Menezes, C. C. (2003). Entrevista individual com cada futuro cônjuge no último semestre antes do casamento. Instrumento não publicado, Universidade Federal do Rio Grande do Sul, Porto Alegre.

Lopes, D. P. L., \& Valle, E. R. M. (2001). A organização familiar e o acontecer do tratamento da criança com câncer. In E. R. M. Valle (Ed.), Psico-oncologia pediátrica (pp. 13-74). São Paulo: Casa do Psicólogo.

Minuchin, S. (1990). Famílias: Funcionamento e tratamento. Porto Alegre: Artmed.

Minuchin, S., \& Fishman, H. C. (1990). Técnicas em terapia familiar. Porto Alegre: Artmed.

Mossman, C., Wagner, A., \& Féres-Carneiro, T. (2006). Qualidade conjugal: Mapeando conceitos. Paidéia, 16, 315-325.

Nichols, W. C. (2005). The first years of marital commitment. In M. Harway (Ed.), Handbook of couples therapy (pp. 28-43). Hoboken: Jonh Willey \& Sons.

Núcleo de Infância e Família - NUDIF (1998). Entrevista de dados demográficos do casal. Instrumento não publicado, Universidade Federal do Rio Grande do Sul, Porto Alegre.

Olson, D. H. (1991). Tipos de familia, estrés familiar y satisfacción con la familia: Una perspectiva del desarrollo familiar. In C. J. Falicov (Ed.), Transiciones de la familia: Continuidad y cambio en el ciclo de vida (pp. 99-129). Buenos Aires: Amorrortu.

Olson, D. H. (2000). Circumplex model of marital and family systems. Journal of Family Therapy, 22, 144-167.

Patterson, J. M. (2002). Integrating family resilience and family stress theory. Journal of Marriage and Family, 64, 349-360.

Patterson, J. M., Holm, K. E., \& Gurney, J. G. (2004). The impact of childhood cancer on the family: A qualitative analysis of strains, resources, and coping behaviors. Psycho-Oncology 13, 390-407.

Patton, M. Q. (2002). Qualitative research and evaluation methods. Thousand Oaks, CA: Sage Publications.

Rando, T. (1985). Bereaved parents: Particular difficulties, unique factors, and treatment issues. Social Work, 30, 19-23.

Rech, B. C. S., \& Lopes, R. C. S. (2007). Entrevista sobre o impacto da doença grave de um filho sobre a relação conjugal. Instrumento não publicado, Universidade Federal do Rio Grande do Sul, Porto Alegre.

Reis, R. S., Santos, M. O., \& Thuler, L. C. S. (2007). Incidência de tumores pediátricos no Brasil. Revista Brasileira de Cancerologia, 53, 5-15.

Ríos-González, J. A. (2005). Los ciclos vitales de la familia y de la pareja: Crises u oportunidades? Madrid: Editorial CCS.

Rivero-Vergne, A., Berrios, R., \& Romero, I. (2008). Cultural aspects of the Puerto Rican cancer experience: The mother as the main protagonist. Qualitative Health Research, 18, 811-820.

Robson, C. (1993). Real world research: A resource for social sciences and practioner researcher. Oxford: Blackwell.

Rodrigues, K. E., \& De Camargo, B. (2003). Diagnóstico precoce do câncer infantil: Responsabilidade de todos. Revista da Associação Médica Brasileira, 49, 29-34.

Rolland, J. S. (1995). Doença crônica e o ciclo de vida familiar. In B. Carter, \& M. McGoldrick (Eds.), As mudanças do ciclo de vida familiar: Uma estrutura para a terapia familiar (pp. 373-391). Porto Alegre: Artes Médicas.
Rolland, J. S. (1998). Ajudando famílias com perdas antecipadas. In F. Walsh \& M. McGoldrick (Eds.), Morte na família: Sobrevivendo às perdas (pp. 166-186). Porto Alegre: Artmed.

Rosman, B. L. (1991). El desarrollo familiar y el impacto de la enfermedad crónica de un hijo. In C. J. Falicov (Ed.), Transiciones de la familia: Continuidad y cambio en el ciclo de vida (pp. 405-428). Buenos Aires: Amorrortu.

Satir, V. (1993). Terapia do grupo familiar. Rio de Janeiro: Francisco Alves.

Schwab, R. (1998). A child's death and divorce: Dispelling the myth. Death Studies, 22, 445-468.

Shapiro, A. F., Gottman, J. M., \& Carrère, S. (2000). The baby and the marriage: Identifying factors that buffer against decline in marital satisfaction after the first baby arrives. Journal of Family Psychology, 14, 59-70.

Silva, F. M., Jacob, E., \& Nascimento, L. C. (2011). Impact of childhood cancer on parents' relationships: An integrative review. Journal of Nursing Scholarship, 42, 250-261.

Silva, I. M., \& Lopes, R. C. S. (2011). Relação conjugal no contexto da reprodução assistida: $\mathrm{O}$ tratamento e a gravidez. Psicologia: Teoria e Pesquisa, 27, 35-44.

Sloper, P. (1996). Needs and responses of parents following the diagnosis of childhood cancer. Child: Care, Health and Development, 22, 187-202.

Stake, R. E. (1994). Case studies. In N. Denzin \& Y. Lincoln (Eds.), Handbook of qualitative research (pp. 236-247). London: Sage.

Steffen, B. C., \& Castoldi, L. (2006). Sobrevivendo à tempestade: A influência do tratamento oncológico de um filho na dinâmica conjugal. Psicologia Ciência e Profissão 26, 406-425.

Stierlin, H., Weber, G., Schmidt, G., \& Simon, F. B. (1986). Features of families with major affective disorders. Family Process, 25, 325-336.

Tudge, J., \& Frizzo, G. F. (2002). Classificação baseada em Hollingshead do nível socioeconômico das famílias do estudo longitudinal de Porto Alegre: Da gestação à escola. Manuscrito não publicado, Universidade Federal do Rio Grande do Sul, Porto Alegre.

Walsh, F. (2002). Casais saudáveis e casais disfuncionais: Qual a diferença? In M. Andolfi (Ed.), A Crise do casal: Uma perspectiva sistêmico-relacional (pp.13-28). Porto Alegre: Artmed.

Walsh, F. (2006). Strengthening family resilience. New York: The Guildford Press.

Walsh, F., \& McGoldrick, M. (1998). Um tempo para chorar: A morte e o ciclo de vida familiar. In F. Walsh \& M. McGoldrick (Ed.), Morte na familia: Sobrevivendo às perdas (pp. 56-77). Porto Alegre: Artmed.

Yin, R. K. (2005). Estudo de caso: Planejamento e métodos. Porto Alegre: Bookman.

Recebido em 16.12.2011

Primeira decisão editorial em 12.04.2012

Versão final em 23.05.2012

Aceito em 27.08.2012 